Artículos

\title{
Uma abordagem sobre a aplicação da Teoria da Resposta ao Item nas avaliações de aprendizagem do ensino contábil brasileiro*
}

Un abordaje sobre la aplicación de la Teoría de la Respuesta al Item en las evaluaciones de aprendizaje de la enseñanza contable brasileña

An approach on the application of Item Response Theory in learning assessments of Brazilian accounting teaching

Mauricio Corrêa da Silva ${ }^{\mathrm{a}}$

Universidade Federal do Rio Grande do Norte, UFRN,

DOI: https://doi.org/10.11144/Javeriana.cc20-50.aatr

Brasil

prof.mauriciocsilva@gmail.com

ORCID: http://orcid.org/0000-0003-2036-5237

Recepção: 06 Fevereiro 2019

João Carlos Hipólito Bernardes do Nascimento

Universidade Federal do Piaui, UFPI, Brasil

ORCID: http://orcid.org/0000-0003-3505-372X

José Dionisio Gomes da Silva

Universidade Federal do Rio Grande do Norte, UFRN,

Brasil

ORCID: http://orcid.org/0000-0002-7289-0220

José Ricardo Maia de Siqueira

Universidade Federal do Rio de Janeiro, Brasil

ORCID: http://orcid.org/0000-0001-5219-6621

\section{Resumo:}

O presente estudo discute as contribuições da aplicação da Teoria da Resposta ao Item --TRI- nas avaliações de aprendizagem do ensino contábil brasileiro. A TRI possibilita a estimação, além da habilidade do respondente, dos parâmetros de dificuldade, discriminação e acertos casuais de cada item. Como resultado das discussões teóricas, notou-se que, entre os principais benefícios provenientes da aplicação da TRI no ensino contábil, destacam-se: o desenvolvimento de avaliações que capturam os parâmetros dos itens; a elaboração de bancos de itens que possibilitará a aplicação de provas equivalentes em datas distintas, a identificação de itens enviesados evitará problemas de injustiça social e a equiparação de escores proporcionará uma avaliação comparativa mais adequada. Assim, os artigos analisados justificam a abordagem da aplicação da técnica da TRI nas avaliações de aprendizagem do ensino contábil brasileiro pelos elementos problematizados na formação pedagógica dos docentes do Curso de Graduação em Ciências Contábeis.

Códigos JEL: M40, M49.

Palavras-chave: Avaliação do ensino superior, teoria de resposta ao item, ensino contábil.

\section{Resumen:}

Este estudio analiza las contribuciones de la aplicación de la Teoría de respuesta al ítem -TRI- en evaluaciones de aprendizaje de la educación contable brasileña. El TRI permite la estimación, además de la capacidad del encuestado, de los parámetros de dificultad, discriminación y golpes casuales de cada ítem. Como resultado de las discusiones teóricas, se observó que entre los principales beneficios derivados de la aplicación de TRI en la educación contable, se destacan los siguientes: el desarrollo de evaluaciones que capturan los parámetros de los ítems, la elaboración de bancos de ítems que permitirán la aplicación de evidencia equivalente en diferentes fechas, la identificación de elementos sesgados evitará problemas de injusticia social y las puntuaciones equivalentes proporcionarán una evaluación comparativa más adecuada. Así, los artículos analizados justifican el enfoque de la aplicación de la técnica TRI en las evaluaciones de aprendizaje de la educación contable brasileña por los elementos problematizados en la

\section{Autor notes:}

a Autor para correspondência. Correio eletrônico: prof.mauriciocsilva@gmail.com 
formación pedagógica de los docentes del Curso de Licenciatura en Contabilidad.

Códigos JEL: M40, M49.

Palabras-chave: evaluación de la enseñanza superior, teoría de respuesta al item, enseñanza contable.

\section{Abstract:}

This study discusses the contributions of the application of Item Response Theory -IRT- in learning assessments of Brazilian accounting education. The IRT allows the estimation, in addition to the ability of the respondent, of the difficulty parameters, discrimination and casual hits of each item. As a result of the theoretical discussions, it was noted that, among the main benefits arising from the application of IRT in accounting education, the following stand out: the development of assessments that capture the parameters of the items; the elaboration of item banks that will allow the application of equivalent evidence on different dates; Identifying skewed items will avoid problems of social injustice and matching scores will provide a more appropriate comparative assessment. Thus, the analyzed articles justify the approach of the application of the IRT technique in the learning evaluations of the Brazilian accounting education by the problematized elements in the pedagogical formation of the teachers of the Undergraduate Course in Accounting.

JEL Codes: M40, M49.

Keywords: Higher education evaluation, item response theory, accounting teaching.

\section{INTRODUÇÃO}

A formação dos professores para o ensino superior é tema de constantes debates. Especificamente no ensino superior de Ciências Contábeis, esse tema da formação também tangencia diferentes concepções. A formação no bacharelado em Ciências Contábeis seguido de cursos de especialização e, de forma restrita, nos cursos de mestrado e doutorado identifica-se como únicas exigências para o ingresso na carreira de professor pelos órgãos reguladores do sistema educacional brasileiro (Laffin \& Gomes, 2016).

O processo de reflexão sobre a aprendizagem para a docência no ensino superior e sobre como estes utilizam as suas experiências docentes para a sua própria constituição profissional, ancorado nos desafios da investigação sobre a docência, tornou-se um importante exercício de olhar para o contexto onde os sujeitos se fazem profissionais (Pryjma \& Oliveira, 2016). Os professores universitários geralmente desconhecem a complexidade do processo de ensino e aprendizagem, ainda que tenham passado por processos formativos em nível de mestrado e doutorado (Hillen, Laffin \& Ensslin, 2018).

As estratégias mais utilizadas pelos docentes dos cursos de graduação em Ciências Contábeis no processo do ensino-aprendizagem são: aulas expositivas, estudo de caso, leitura de textos (Leal \& Borges, 2016; Gilioli, Cassaro, Santos, Amaral, Cardoso, \& Benedicto, 2016). Para Brighenti, Biavatti, \& Souza (2015), na percepção dos alunos do Curso de Ciências Contábeis da Universidade Comunitária da Região de Chapecó em Santa Catarina, Brasil, o método e a técnica de ensino considerado mais eficaz para o aprendizado é a resolução de exercício.

Quanto às avaliações dos alunos, Turra, Enricone, Sant’Anna \& André (1989) relatam que as funções gerais da avaliação são: fornecer as bases para o planejamento, possibilitar a seleção e a classificação de pessoal (professores, alunos, especialistas etc.), ajudar políticas e práticas curriculares. Como funções específi cas da avaliação, segundo as autoras são: facilitar o diagnóstico, melhorar a aprendizagem e o ensino (controle), estabelecer situações individuais de aprendizagem e promover, agrupar alunos (classificação).

Os métodos de avaliação adotados pelos docentes são, sem dúvida, um fator importante que pode influenciar o processo de aprendizagem de forma negativa ou positiva (Pereira \& Flores, 2012). De acordo com Matos, Cirino, Brown \& Leite (2013), se não conseguir responder à questão de como os estudantes estão percebendo a avaliação no ensino superior, algumas reformas avaliativas podem não ter o resultado esperado e a eficácia das práticas avaliativas está condicionada a forma como eles entendem e, consequentemente, respondem a avaliação.

A coerência entre o que o professor ensina e a forma como ele avalia a aprendizagem, conforme argumentos de Silva, Matos \& Almeida (2014), é o primeiro fator para encaminhar um bom processo educativo. Um bom processo avaliativo depende dos três principais tipos de avaliação existentes. A avaliação 
diagnóstica permite conhecer o aluno, seus gostos, seus hábitos e preferências; a formativa permite ajustar o processo de ensino-aprendizagem à realidade de aprendizado do aluno; e a somativa permite classificar o nível de aprendizado dos alunos.

Batista \& Ibiapina (2016) esclarecem que as práticas avaliativas realizadas no ensino superior têm se caracterizado como predominantemente tradicionais, ou seja, servem como instrumentos de medição da capacidade dos alunos em reproduzir o conteúdo transmitido pelos professores. Observa-se a carência de práticas avaliativas dinâmicas, uma vez que, a ausência de formação continuada gera a falta de conhecimentos pedagógicos necessários à aplicação desse tipo de avaliação, gerando um círculo vicioso em que os professores ensinam e avaliam seus alunos como foram ensinados e avaliados.

Para Farias \& Araújo (2016), os programas de Pós-graduação em contabilidade no Brasil continuam com foco na formação de pesquisadores, não sendo a formação docente suficientemente oferecida nos cursos de mestrado e doutorado da área. De acordo com Laffin \& Gomes (2016), entende-se que para ser contador não há necessidade de ter formação pedagógica, mas para ser professor de Ciências Contábeis, torna-se imprescindível a compreensão da natureza pedagógica da função docente.

Para os alunos ingressarem no ensino superior em diversas universidades no Brasil (bacharelado em ciências contábeis, administração etc.), os candidatos deverão realizar as provas do Exame Nacional do Ensino Médio -ENEM- , elaboradas pelo Instituto Nacional de Estudos e Pesquisas Educacionais Anísio Teixeira -INEP-do Ministério da Educação, corrigidas com a aplicação da técnica de Teoria da Resposta ao Item -TRI ou IRT em inglês-. Segundo Moreira Júnior (2010), a Teoria da Resposta ao Item -TRItornou-se conhecida ao público leigo no Brasil através da sua utilização em larga escala no ENEM. Contudo, sua utilização que abrange uma maior quantidade possível de aplicações distintas, ocorre desde 1995.

Andrade, Tavares \& Valle (2000) esclarecem que a TRI é usada no campo de testes em vários países. No Brasil, a TRI foi usada pela primeira vez em 1995 na análise dos dados do Sistema Nacional de Ensino Básico-SAEB-. A introdução da TRI permitiu que os desempenhos de alunos de 4a. e 8a. séries do Ensino Fundamental e de 3a. série do Ensino Fundamental pudessem ser comparados e colocados em uma escala única de conhecimento. A partir dos resultados obtidos no SAEB, outras avaliaçóes em larga escala, como por exemplo o Sistema de Avaliação de Rendimento Escolar do Estado de São Paulo -SARESP-, também foram planejadas e implementadas de modo a serem analisadas através da TRI.

Para Toland (2014) a Teoria da Resposta ao Item -TRI-, é uma técnica psicométrica utilizada no desenvolvimento, avaliação, melhoria e pontuação de escalas de múltiplos itens. Segundo Harvey (2016), os modelos da TRI geralmente têm uma visão mais realista de como as respostas dos itens estão relacionadas às características subjacentes do que a Teoria dos Testes Clássicos.

Nessa perspectiva, partindo do entendimento de que a titulação em Strito Sensu em Contabilidade não oferece a capacitação necessária para o exercício da docência, ponderando que os métodos de avaliação mostram um fator preponderante no processo de aprendizagem, a presente pesquisa discute as contribuições da aplicação da TRI nas avaliações de aprendizagem do ensino contábil brasileiro, e como os docentes poderá utilizá-la.

Justifica-se o recorte em função da complexidade de que se reveste a avaliação de aprendizagem e a formação docente de natureza pedagógica dos professores da área contábil. Com esta delimitação, a presente pesquisa analisa as contribuições de publicações que discutem questões relacionadas com o ensino superior e de modo especial o ensino contábil e as aplicações diversas da TRI.

\section{REFERENCIAL TEORICO}

Nessa etapa da pesquisa, é realizada um breve reporte do processo de avaliação do ensino superior, bem como especificamente do ensino contábil no contexto brasileiro (Tabelas 1 e 2). Em seguida, aborda-se a 
Teoria da Resposta ao Item -TRI-, destacando alguns dos principais softwares que suportam a aplicação da técnica, além dos objetivos de sua aplicação em diversas áreas no processo de avaliação (Tabelas 3 e 4 ).

\section{Processo de Avaliação no Ensino Superior}

As principais avaliações utilizadas no processo de avaliação do ensino-aprendizagem são: provas ou testes subjetivos (questões de verdadeiro-falso, múltipla escolha e preenchimento de lacunas); prova descritiva (comentários); prova oral; prova criativa (consulta de fontes); produções individuais ou coletivas; seminários etc. $\mathrm{Na}$ Tabela 1, reportam-se os artigos analisados em periódicos brasileiros e internacionais sobre o processo de avaliação no ensino superior.

TABELA 1_1

Análises publicadas em periódicos brasileiros e internacionais sobre o processo de avaliação no ensino superior

\begin{tabular}{|c|c|}
\hline Autores & Principais observações \\
\hline $\begin{array}{l}\text { Borba, Ferri \& Hostins } \\
\text { (2007) }\end{array}$ & $\begin{array}{l}\text { O professor não está livre do ato de julgar, porque avaliar é julgar algo } \\
\text { ou alguém quanto ao seu valor. É um ato que pode expressar } \\
\text { classificação, apreciação ou orientação em direção ao futuro. Os } \\
\text { critérios de avaliação, previamente negociados, permitem ao professor } \\
\text { acompanhar não só a atividade, mas a aprendizagem de seus alunos, } \\
\text { identificando na complexidade do real, as capacidades que estão sendo } \\
\text { construídas. Os registros desta ação são mais interpretativos, focando as } \\
\text { múltiplas relações que interferem na aprendizagem dos alunos, seus } \\
\text { avanços e dificuldades. }\end{array}$ \\
\hline Sordi \& Ludke (2009) & $\begin{array}{l}\text { A aprendizagem da avaliação precisa ser elevada à condição estratégica } \\
\text { nos processos de formação docente, sejam eles iniciais ou permanentes, } \\
\text { e isso inclui o exercício da autoavaliação e a avaliação pelos pares. Um } \\
\text { professor familiarizado com estas práticas ganha condição de bem } \\
\text { ensinar e bem realizar a avaliação de/com seus estudantes. }\end{array}$ \\
\hline Garcia (2009) & $\begin{array}{l}\text { As práticas de avaliação exercidas pelos professores apresentam } \\
\text { diversas implicações sobre as atitudes de aprendizagem mostradas pelos } \\
\text { estudantes. Quando os professores optam por avaliar a aprendizagem } \\
\text { dos alunos por meio de provas escritas, ao final do bimestre, eles } \\
\text { estabelecem algumas condições, projetam expectativas e desenham uma } \\
\text { tabela a ser interpretado pelos estudantes. Tal interpretação reflete-se no } \\
\text { modo de agir dos estudantes em sala de aula -como diferenciam } \\
\text { conteúdo do currículo e desenvolvem hábitos de estudo-e, de modo } \\
\text { mais amplo, na aprendizagem, que exerce papel considerável em suas } \\
\text { formações. }\end{array}$ \\
\hline
\end{tabular}


TABELA 1_2

Análises publicadas em periódicos brasileiros e internacionais sobre o processo de avaliação no ensino superior

\begin{tabular}{ll}
\hline \multicolumn{1}{c}{ Autores } & \multicolumn{1}{c}{ Principais observações } \\
\hline & Os professores devem buscar métodos avaliativos diversificados que \\
propiciem um maior conhecimento do seu aluno, além de procurar \\
Pinheiro \& Santos & $\begin{array}{l}\text { entender que a avaliação deve ser vista como parte integrante do } \\
\text { processo de ensino e aprendizagem e não como a finalização de } \\
\text { conteúdos estudados. }\end{array}$
\end{tabular}

\begin{tabular}{ll}
\hline & $\begin{array}{l}\text { As concepções e práticas de avaliação não consideram o contexto mais } \\
\text { amplo nem suas interligações e têm se sustentado na falácia da } \\
\text { igualdade de oportunidades, da educação como meio de auto realização, } \\
\text { Sem considerar os condicionamentos sociopoliticos e econômicos e as } \\
\text { condições de efetivação do processo ensino aprendizagem na escola. }\end{array}$ \\
\hline $\begin{array}{l}\text { Silva, Matos \& } \\
\text { Almeida (2014) }\end{array}$ & $\begin{array}{l}\text { A avaliação não deve ser vista apenas como uma prova com questões } \\
\text { abertas e fechadas ou como um momento de tensão e julgamento pelos } \\
\text { alunos, e sim como um momento de análise e feedback das } \\
\text { aprendizagens adquiridas. }\end{array}$ \\
\hline $\begin{array}{l}\text { Brighenti, Biavatti \& } \\
\text { Souza (2015) }\end{array}$ & $\begin{array}{l}\text { Na percepção dos alunos, os trabalhos individuais foram considerados } \\
\text { muito eficaz para o seu aprendizado de forma a superar as provas e os } \\
\text { trabalhos em grupo. }\end{array}$ \\
\hline
\end{tabular}

elaborado pelos autores

TABELA 1_3

Análises publicadas em periódicos brasileiros e internacionais sobre o processo de avaliação no ensino superior

\begin{tabular}{ll}
\hline \multicolumn{1}{c}{ Autores } & \multicolumn{1}{c}{ Principais observações } \\
\hline $\begin{array}{l}\text { Popescu-Mitroia, } \\
\text { Todorescu \& }\end{array}$ & $\begin{array}{l}\text { O portfólio é um método alternativo de avaliação com valor formativo } \\
\text { para os alunos. O portfólio lida com os aspectos do campo de estudo, } \\
\text { portanto é recomendado para qualquer sistema educacional centrado na } \\
\text { competência. Além disso, permite a avaliação de alvos cognitivos mais } \\
\text { complexos. }\end{array}$ \\
\hline $\begin{array}{l}\text { Leeuwenkamp, Brinke } \\
\text { \& Kester (2017) }\end{array}$ & $\begin{array}{l}\text { As instituições de ensino superior têm a obrigação de garantir a } \\
\text { qualidade da avaliação. Esta é uma tarefa dificil porque não existe uma } \\
\text { conceituação clara e abrangente da qualidade da avaliação. }\end{array}$ \\
\hline $\begin{array}{l}\text { Keinänen, Ursin \& } \\
\text { Nissinen (2018) }\end{array}$ & $\begin{array}{l}\text { É necessário atualizar práticas pedagógicas e desenvolver ferramentas } \\
\text { de avaliação para medir e desenvolver a capacidade de inovação de uma } \\
\text { pessoa. }\end{array}$ \\
\hline $\begin{array}{l}\text { Os testes de múltipla escolha são indiscutivelmente o tipo mais popular } \\
\text { de avaliação na educação. Um item de múltipla escolha eficaz exigirá } \\
\text { que os alunos pensem de maneira produtiva para o aprendizado e } \\
\text { forneçam uma medida válida para determinar se a habilidade, o } \\
\text { conhecimento ou ambos foram adquiridos. }\end{array}$
\end{tabular}

elaborado pelos autores

$\mathrm{Na}$ Tabela 1, destacam questões relevantes sobre o processo de avaliação. De uma forma geral, podese perceber que os estudos sinalizam pela necessidade de atualização de práticas pedagógicas, devendo os docentes buscar e desenvolver métodos avaliativos diversificados. A Teoria da Resposta ao Item -TRI- pode ser incluída nesta metodologia. 


\section{Ensino Contábil}

A exigência para ser docente do Curso de Graduação em Ciências Contábeis no Brasil é a formação nos cursos de metrado e doutorado. Na Tabela 2, citam-se os artigos analisados em periódicos brasileiros sobre questões do ensino contábil.

TABELA 2_1

Análises publicadas em periódicos brasileiros sobre o ensino contábil

\begin{tabular}{|c|c|}
\hline Autores & Principais conclusões \\
\hline Slomski (2007) & $\begin{array}{l}\text { Necessidade de estudos empiricos que abordem às questões de como } \\
\text { os professores de Ciências Contábeis constroem a prática pedagógica } \\
\text { e realizam a transposição didática da formação que receberam. }\end{array}$ \\
\hline Andere \& Araújo (2008) & $\begin{array}{l}\text { Necessidade e importância dos cursos de Programas de Pós- } \\
\text { Graduação Stricto Sensu em Contabilidade oferecerem disciplinas } \\
\text { voltadas para a área de ensino. }\end{array}$ \\
\hline $\begin{array}{l}\text { Peleias, Mendonça, Slomski \& } \\
\text { Fazenda (2011) }\end{array}$ & $\begin{array}{l}\text { Os docentes de Controladoria percebem a importância da } \\
\text { interdisciplinaridade para a prática pedagógica, a melhoria da } \\
\text { qualidade de ensino e a formação discente, mas persiste uma } \\
\text { distância entre o falado, o pensado e o efetivamente praticado no } \\
\text { contexto universitário. }\end{array}$ \\
\hline $\begin{array}{l}\text { Ott, Cunha, Cornacchione } \\
\text { Júnior \& De Luca (2011) }\end{array}$ & $\begin{array}{l}\text { Necessidade de maior exposição a métodos de ensino que } \\
\text { privilegiem o desenvolvimento do raciocínio crítico e as habilidades } \\
\text { de comunicação e maior exposição as novas demandas do futuro } \\
\text { mercado de trabalho global. }\end{array}$ \\
\hline $\begin{array}{l}\text { Araújo \& Moraes Júnior } \\
\text { (2012) }\end{array}$ & $\begin{array}{l}\text { Os resultados mostraram que o portfólio foi capaz de promover a } \\
\text { mobilização do estudante em busca da própria aprendizagem na } \\
\text { disciplina Administração Financeira, ministrada no Curso de } \\
\text { Ciências Contábeis, bem como o desenvolvimento de uma } \\
\text { consciência crítica a respeito do seu rendimento escolar. }\end{array}$ \\
\hline
\end{tabular}

elaborado pelos autores 
TABELA 2_3

Análises publicadas em periódicos brasileiros sobre o ensino contábil Autores Principais conclusões

\begin{tabular}{ll}
\hline \multicolumn{1}{c}{ Autores } & \multicolumn{1}{c}{ Principais conclusões } \\
\hline & $\begin{array}{l}\text { A maioria dos docentes de Ciências Contábeis da cidade do Rio de } \\
\text { Janeiro que participaram da pesquisa responderam que não aplicam } \\
\text { ou não estão familiarizados com as técnicas progressistas de ensino. } \\
\text { Os principais motivos residem na ausência ou deficiência de } \\
\text { formação pedagógica, desconhecimento das técnicas e ambiente } \\
\text { inadequado. }\end{array}$ \\
\hline $\begin{array}{l}\text { Brighenti, Biavatti \& Souza } \\
\text { (2015) }\end{array}$ & $\begin{array}{l}\text { Necessidade de os professores atentarem-se aos métodos de ensino } \\
\text { que são mais eficazes para a aprendizagem dos alunos, para assim }\end{array}$ \\
\hline melhorar a relação entre ensino-aprendizagem. \\
\hline Gilioli et al. (2016) & $\begin{array}{l}\text { Aulas expositivas e práticas são predominantes no ensino contábil, } \\
\text { seguidas pelo estudo de caso e livro texto-leitura. A avaliação das } \\
\text { metodologias que balizam o ensino-aprendizagem nas salas de aulas, } \\
\text { em conjunto com a formação e o exercicio da docência, são fatores } \\
\text { que precisam de estudos teóricos-empiricos que contribuam para a } \\
\text { evolução do ensino da contabilidade. }\end{array}$ \\
\hline Os programas de Pós-graduação em contabilidade no Brasil \\
continuam com foco na formação de pesquisadores, não sendo a \\
formação docente suficientemente oferecida nos cursos de mestrado \\
e doutorado da área.
\end{tabular}

elaborado pelos autores

TABELA 2_3

Análises publicadas em periódicos brasileiros sobre o ensino contábil

\begin{tabular}{cl}
\hline \multicolumn{1}{c}{ Autores } & \multicolumn{1}{c}{ Principais conclusões } \\
\hline & As estratégias de ensino que os discentes consideram mais \\
Leal \& Borges (2016) & significativos para o aprendizado na Contabilidade Gerencial são: \\
& Trabalho em Grupo/Seminário; Leitura/Estudo Dirigido e Aula \\
& Expositiva.
\end{tabular}

Existência de deficiência nos planos de ensino sobre a definição de critérios de avaliação, não deixando claro ao aluno quais serão os critérios a serem avaliados quanto à aplicação da avaliação e, por

Picolli \& Biavatti (2017) consequência, a atribuição da nota. Foi constatado que os exercícios são a principal estratégia de ensino utilizada pelos docentes como avaliação formativa dos alunos e que a prova ainda é o instrumento de avaliação mais utilizado como medida somativa.

O objetivo da formação docente ainda não cumpre sua finalidade como proposição efetiva dessa formação. A área de Ciências

Hillen, Laffin \& Ensslin Contábeis, no Brasil, ao ter como incipiente a pesquisa no âmbito da (2018) formação do professor de Contabilidade, passa a reconhecer a necessidade dessa formação por meio dos programas de pósgraduação Stricto Sensu, sem, contudo, implementar organicidade.

Farias et al. (2018)

Necessidade do aperfeiçoamento da prática docente, uma vez que identificar as competências de um bom professor pode auxiliar em seu processo formativo.

elaborado pelos autores. 
Observa-se na Tabela 2, relatos sobre a formação do docente dos Cursos de Graduação em Ciências Contábeis, os quais permitem inferir que os cursos de metrado e doutorado não apresentam a formação docente suficiente para o exercício das atividades de ensino. Assim, se existem problemas relacionados com a formação desses docentes, pode-se concluir que o processo de avaliação do ensino-aprendizagem está inserido neste rol, o que justifica a abordagem desta investigação.

Ademais, dada a iminente necessidade de repensar o processo de ensino-aprendizagem de forma a adequar o ensino em contabilidade à formação do conjunto de habilidades técnicas e genéricas requeridas dos contadores, conforme a International Education Standards 3-, Professional Skills and General Education, reforça-se a relevância da condução do presente estudo.

\section{Teoria da Resposta ao Item}

A Teoria da Resposta ao Item -TRI-, de acordo com Pasquali (1996) já tem uma longa história. Ela iniciou com os trabalhos de Lord nos anos de 1952 e 1953 nos Estados Unidos e com Rasch em 1960 na Holanda, que a utilizaram para testes de desempenho e de aptidão. Contudo, apenas, a partir de meados dos anos 80 , a TRI vem se tornando a técnica predominante no campo dos testes. A razão da demora desta teoria em ser amplamente utilizada em psicometria consiste na enorme complexidade de manipulação de seus modelos matemáticos, inviáveis sem os requintados programas de computador, e estes só começaram efetivamente a entrar no mercado nos anos 80.

De acordo com Andrade, Tavares e Valle (2000), a TRI é usada em várias áreas do conhecimento e de forma particular na avaliação educacional. A TRI propõe modelos para os traços latentes, ou seja, características do indivíduo que não podem ser observadas diretamente. Esse tipo de variável deve ser inferida a partir da observação de variáveis secundárias que estejam relacionadas a ela. O que esta metodologia sugere são formas de representar a relação entre a probabilidade de um indivíduo dar uma certa resposta a um item e seus traços latentes, proficiências ou habilidades na área de conhecimento avaliada.

Segundo Araújo, Andrade e Bortolotti (2009), a TRI que, a princípio, veio completar limitações da Teoria Clássica de Medidas, é empregada em larga escala na medida de traços psicológicos. O ponto principal da TRI é que ela leva em consideração o item particularmente, sem relevar os escores totais; portanto, as conclusões não dependem apenas do teste ou questionário, mas de cada item que o compõe.

Para Andrade, Laros e Gouveia (2010), a TRI é conhecida como a Teoria da Curva Característica do Item ou Teoria do Traço Latente. O traço latente é uma característica não observável do sujeito, que determina sua forma de responder ao teste que é apresentado. Um modelo de traço latente especifica a relação entre o rendimento observável de um examinando em um teste e o traço latente não observável ou habilidade, que se supõe subjacente ao rendimento no teste.

Assim, a TRI possibilita modelar a probabilidade de resposta do item "i" em função do "construto latente" $\theta_{\mathrm{j}}$ (theta), do respondente “j” e dos parâmetros que expressam as propriedades dos itens, isto é, parâmetros de discriminação (ai) e de dificuldade (bi), nos modelo logístico de dois parâmetros - 2PLM (Lord \& Novick, 1968; Hambleton, Swaminathan, \& Rogers, 1991; Baker, 2001; Reckase, 2009).

O parâmetro ai compreende o poder de segregação do item por nível de habilidade investigada, logo, sendo que, quanto maior o indicador, mais elevado o poder discriminatório do item (Hambleton, Swaminathan, \& Rogers, 1991). Relativo ao parâmetro $b_{i}$, este é estimado na mesma escala do construto latente, assim, relaciona-se diretamente ao nível de theta $\left(\theta_{j}\right)$ necessário para que a probabilidade de acerto do item seja de 0,50 (Andrade, Tavares, \& Valle, 2000). Em outras palavras, quando $(b)<\theta_{j}$, maior será a probabilidade do respondente apresentar a resposta correta ao item; quando $(b)>\theta_{j}$, o participante da avaliação apresentará maior probabilidade de errar o item; e, por fim, se $(b)=\theta_{j}$, entende-se que o respondente deve apresentar nível intermediário de habilidade (percentil de 50) para acertar o item (Andrade, Tavares, \& Valle, 2000). 
Já relativo ao $\theta$ j, este é estimado como a distribuição normal das habilidades dos respondentes, com padronização similar aos escores z, com média igual a 0 (zero) e desvio padrão igual a 1 (um), sendo que o $\theta j$ apresenta valores esperados oscilando de -3 a +3 (Reckase, 2009). A estimação do $\theta_{j}$ é realizada por meio do Método da Máxima Verossimilhança através da utilização do algoritmo EM (Expectation Maximization), via modelo logístico de dois parâmetros (two-parameter logistic model - 2PLM).

Mais recentemente, foi desenvolvido o modelo logístico com três parâmetros (three-parameter logistic model - 3PLM), incorporando o parâmetro de ao acerto casual (chute) ( $c_{i}$ ). Segundo Baker (2001), o parâmetro ci captura a probabilidade do respondente “j”, que apresenta baixo nível $\theta j$, responda corretamente o item “i”. Em outras palavras, o parâmetro ci captura a chance do respondente com baixo nível de $\theta_{j}$ apresentar a resposta correta ao item específico.

Nessa perspectiva, uma vez que é esperado que respondentes com alto nível de $\theta \mathrm{j}$ apresentem padrão de resposta coerente, acertando questões fáceis, medianas e difíceis de forma consistente, por extensão, não espera-se que um indivíduo com baixo $\theta \mathbf{j}$ acerte itens difíceis (incompatível o nível de habilidade latente disponível). Assim, pode-se notar que o parâmetro ci relaciona-se diretamente ao padrão de respostas apresentado pelo indivíduo (INEP, 2011). Assim, itens com boa "qualidade" apresentam baixos valores de ci (Baker, 2001). Nesse ponto, pode-se notar que o modelo 3PLM, o nível $\theta_{j}$ é estimado em função do desempenho (quantidade de acertos), os parâmetros estimados dos itens, e o padrão de respostas apresentados (Reckase, 2009).

Segundo Ayala e Santiago (2017), a TRI emergiu como uma abordagem para resolver vários problemas de medição com variáveis latentes, porque permite abordar situações que envolvem uma mistura de subpopulações latentes que são qualitativamente diferentes, mas dentro das quais um modelo de medição é baseado em uma variável latente contínua. As informações para serem usadas nas avaliações da TRI podem ser dados de resposta binária (por exemplo, verdadeiro / falso, concordar / discordar, endosso / não endosso, correto / incorreto, presença / ausência de um comportamento), escalas de resposta Likert, pontuação parcial correta, escalas nominais ou escalas de avaliação.

Diante destas argumentações, as Tabelas 3 e 4 apresentam diversos autores que abordam a Teoria nas diversas áreas do conhecimento. São relatados apenas os objetivos das publicações no intuito de evidenciar as aplicações diversas da TRI. Na Tabela 3, citam-se os artigos analisados em periódicos internacionais. 
TABELA 3_1

Aplicações da Teoria da Resposta ao Item (TRI) publicados em periódicos internacionais

\begin{tabular}{ll}
\hline \multicolumn{1}{c}{ Autores } & \multicolumn{1}{c}{ Objetivo } \\
\hline $\begin{array}{l}\text { Gifford et al. } \\
(2015)\end{array}$ & $\begin{array}{l}\text { Desenvolver um questionário para indicar alterações de declínio cognitivo } \\
\text { subjetivo. }\end{array}$ \\
\hline $\begin{array}{l}\text { Anthony, DiPerna } \\
\text { \& Lei (2016) }\end{array}$ & $\begin{array}{l}\text { Maximizar a eficiência da escala de avaliação do Sistema de Melhoria de } \\
\text { medida de habilidades sociais dos alunos frequentemente usadas na prática e na } \\
\text { pesquisa. }\end{array}$ \\
\hline $\begin{array}{l}\text { Huang et al. } \\
\text { (2017) }\end{array}$ & $\begin{array}{l}\text { Selecionar itens com capacidade discriminativa acima da média e itens mais } \\
\text { informativos sobre o nivel de segurança de organizações e de grupos. }\end{array}$ \\
\hline $\begin{array}{l}\text { Rusch, Lowry, } \\
\text { Mair \& } \\
\text { Treiblmaier } \\
\text { (2017) }\end{array}$ & $\begin{array}{l}\text { Apresentar a teoria da resposta ao item (TRI) como uma coleção de alternativas } \\
\text { viáveis para medir variáveis latentes continuas por meio de indicadores } \\
\text { categóricos, ou seja, variáveis de medida, com vantagens de aplicação sobre o uso } \\
\text { da teoria dos testes clássicos. }\end{array}$ \\
\hline $\begin{array}{l}\text { Heafner \& } \\
\text { Fitchett (2018) }\end{array}$ & $\begin{array}{l}\text { Avaliar itens da história dos EUA de estudantes segregados em raça e gênero para } \\
\text { determinar se houve diferenças nas pontuações dos resultados. }\end{array}$ \\
\hline $\begin{array}{l}\text { Tracey \& Tao } \\
\text { (2018) }\end{array}$ & Examinar respostas de interesse vocacional de 989 adultos. \\
\hline $\begin{array}{l}\text { Marino et al. } \\
\text { (2018) }\end{array}$ & $\begin{array}{l}\text { Desenvolver formulários curtos para avaliar o impacto social de lesões } \\
\text { provocadas por queimaduras. }\end{array}$ \\
\end{tabular}

elaborado pelos autores

INSERIR TABELA 3_2

Aplicações da Teoria da Resposta ao Item (TRI) publicados em periódicos internacionais

\begin{tabular}{|c|c|}
\hline Autores & Objetivo \\
\hline $\begin{array}{l}\text { Matzembacher, } \\
\text { Stangherlin, } \\
\text { Slongo \& Cataldi } \\
(2018)\end{array}$ & $\begin{array}{l}\text { Analisar informações de rastreabilidade e de impactos na confiança de } \\
\text { consumidores de produtos no Brasil. }\end{array}$ \\
\hline $\begin{array}{l}\text { Ayis, Ayerb, } \\
\text { Ashworth \& } \\
\text { Wolfe (2018) }\end{array}$ & $\begin{array}{l}\text { Examinar as propriedades de cada item da escala hospitalar de ansiedade e } \\
\text { depressão percebidas pelos pacientes com AVC. }\end{array}$ \\
\hline $\begin{array}{l}\text { Allega, Leng, } \\
\text { Vaccarino et al. } \\
(2018)\end{array}$ & $\begin{array}{l}\text { Analisar as respostas da entrevista de ritmos biológicos da avaliação em } \\
\text { neuropsiquiatria e suas associações com medidas objetivas de distúrbios do sono } \\
\text { e do ritmo. }\end{array}$ \\
\hline $\begin{array}{l}\text { Hoertel et al. } \\
(2018)\end{array}$ & $\begin{array}{l}\text { Examinar se, ao igualar os niveis de gravidade do sintoma do transtorno de } \\
\text { personalidade narcisista, existem diferenças entre os sexos na probabilidade de } \\
\text { relatar os sintomas de perturbaçốes ou transtornos mentais. }\end{array}$ \\
\hline $\begin{array}{l}\text { Sekely, Taylor \& } \\
\text { Bagby (2018) }\end{array}$ & $\begin{array}{l}\text { Analisar dados de uma grande amostra heterogênea multi-idioma para investigar } \\
\text { se um subconjunto de itens poderia ser selecionado para criar uma versão curta da } \\
\text { entrevista estruturada de Toronto para alexitimia. }\end{array}$ \\
\hline $\begin{array}{l}\text { Crowe et al. } \\
\text { (2018) }\end{array}$ & $\begin{array}{l}\text { Utilizar os métodos de pontuação da Teoria de Resposta ao Item para maximizar } \\
\text { a potência e minimizar o erro na relação curvilínea de autoestima e narcisismo. }\end{array}$ \\
\hline
\end{tabular}


TABELA 3_3

Aplicações da Teoria da Resposta ao Item (TRI) publicados em periódicos internacionais

\begin{tabular}{|c|c|}
\hline Autores & Objetivo \\
\hline $\begin{array}{l}\text { Obbarius et al. } \\
(2018)\end{array}$ & $\begin{array}{l}\text { Avaliar e calibrar o banco final de itens usados para medir a resiliência ao estresse } \\
\text { em populações clínicas. }\end{array}$ \\
\hline $\begin{array}{l}\text { Vincenzi et al. } \\
\text { (2018) }\end{array}$ & $\begin{array}{l}\text { Avaliar a percepção de indicadores de sustentabilidade ambiental por meio de } \\
\text { questionários estruturados aplicados em residentes na Bacia do Paraná III, Brasil. }\end{array}$ \\
\hline Hung (2018) & $\begin{array}{l}\text { Analisar a dimensionalidade e o funcionamento diferencial de itens de gênero com } \\
\text { uma amostra de } 1416 \text { estudantes tailandeses. }\end{array}$ \\
\hline $\begin{array}{l}\text { Muñoz-Merino, } \\
\text { Novillo \& Kloos } \\
\text { (2018) }\end{array}$ & $\begin{array}{l}\text { Descrever dois novos algoritmos para modelagem de habilidades e adaptação de } \\
\text { exercícios que integram a teoria da resposta ao item e o espaço do conhecimento } \\
\text { para ter uma abordagem mais poderosa com mais conhecimento nos modelos e } \\
\text { ao mesmo tempo fornecer uma solução para levar em conta exercícios } \\
\text { paramétricos onde um aluno deve resolver um exercício corretamente várias vezes } \\
\text { para obter proficiência. }\end{array}$ \\
\hline $\begin{array}{l}\text { Schivinski et al. } \\
\text { (2018) }\end{array}$ & $\begin{array}{l}\text { Avaliar o desempenho da medição de critérios de diagnósticos do transtorno do } \\
\text { jogo na Internet. }\end{array}$ \\
\hline $\begin{array}{l}\text { Uto \& Ueno } \\
(2018)\end{array}$ & $\begin{array}{l}\text { Apresentar comparações empíricas de modelos da Teoria da Resposta ao Item na } \\
\text { avaliação de desempenho. }\end{array}$ \\
\hline
\end{tabular}

elaborado pelos autores

TABELA 4_1

Aplicações da Teoria da Resposta ao Item (TRI) publicados em periódicos brasileiros

\begin{tabular}{|c|c|}
\hline Autores & Objetivo \\
\hline $\begin{array}{l}\text { Vendramini \& Dias } \\
(2005)\end{array}$ & $\begin{array}{l}\text { Analisar } 15 \text { questões de múltipla escolha de uma prova de estatística apresentada } \\
\text { na forma de gráficos ou de tabelas estatísticas com amostra de } 413 \\
\text { universitários, selecionados por conveniência, de duas instituições da rede } \\
\text { particular de ensino superior, predominantemente do curso de Psicologia. }\end{array}$ \\
\hline $\begin{array}{l}\text { Sabbag, Bernardi } \\
\text { JR, Goldszmidt \& } \\
\text { Zambaldi (2010) }\end{array}$ & $\begin{array}{l}\text { Desenvolver um instrumento de medida de resiliência composto por } 40 \text { questões } \\
\text { relacionadas a } 11 \text { construtos teoricamente identificados: Otimismo, } \\
\text { Proatividade, Autoestima, Auto eficácia, Flexibilidade, Controle de Emoções, } \\
\text { Controle de Impulsos, Empatia, Tenacidade, Improviso, Autonomia aplicado a } \\
1436 \text { estudantes de um programa de educação continuada em Administração. }\end{array}$ \\
\hline Andriola (2011) & $\begin{array}{l}\text { Avaliar os parâmetros métricos dos itens da prova do Exame Nacional do Ensino } \\
\text { Médio -ENEM- para ingresso nas Universidades Brasileiras. }\end{array}$ \\
\hline $\begin{array}{l}\text { Bortolotti et al. } \\
(2012)\end{array}$ & $\begin{array}{l}\text { Aplicar um modelo cumulativo da teoria da resposta ao item para criar uma } \\
\text { medida de satisfação de } 525 \text { alunos com seus cursos, avaliando também a } \\
\text { satisfação no ensino e criando uma escala de medida. }\end{array}$ \\
\hline $\begin{array}{l}\text { Nascimento, Nossa } \\
\text { \& Balassiano (2013) }\end{array}$ & $\begin{array}{l}\text { Determinar o escore verdadeiro da variável dependente para investigar se o } \\
\text { analfabetismo funcional é um fenômeno relevante, utilizando uma amostra de } \\
\text { alunos concluintes de um curso de graduação em Ciências Contábeis. }\end{array}$ \\
\hline $\begin{array}{l}\text { Rodrigues et al. } \\
\text { (2013) }\end{array}$ & $\begin{array}{l}\text { Analisar instrumento de medição da adesão ao tratamento da hipertensão com } \\
406 \text { pacientes com complicações associadas, atendidos na atenção básica em } \\
\text { Fortaleza, CE, Brasil em } 2011 \text {. }\end{array}$ \\
\hline $\begin{array}{l}\text { Barbetta, Trevisan, } \\
\text { Tavares \& Azevedo } \\
\text { (2014) }\end{array}$ & $\begin{array}{l}\text { Aplicar os modelos da TRI em um processo seletivo de ingresso em uma } \\
\text { Universidade com item unidimensional e multidimensional e selecionar traços } \\
\text { latentes predominantes. }\end{array}$ \\
\hline
\end{tabular}


TABELA 4_2

Aplicações da Teoria da Resposta ao Item (TRI) publicados em periódicos brasileiros

\begin{tabular}{|c|c|}
\hline Autores & Objetivo \\
\hline $\begin{array}{l}\text { Quaresma et al. } \\
\text { (2014) }\end{array}$ & $\begin{array}{l}\text { Padronizar as respostas dos candidatos aos itens do exame vestibular } \\
\text { coordenado pela FUVEST, nos seis cursos de graduação da Escola Superior de } \\
\text { Agricultura Luiz de Queiroz, da Universidade de São Paulo, no ano de 2012, } \\
\text { considerando somente a primeira fase do processo seletivo, para construção de } \\
\text { uma escala de proficiências que melhor avalie os sujeitos. }\end{array}$ \\
\hline $\begin{array}{l}\text { Machado \& Barbetta } \\
\text { (2015) }\end{array}$ & $\begin{array}{l}\text { Identificar nos questionários de contextualização do Sistema Nacional de } \\
\text { Avaliação da Educação Básica de } 2011 \text { grupos de itens que propiciaram a } \\
\text { mensuração de fatores associados à aprendizagem, os quais viabilizaram a } \\
\text { construção de escalas de medidas. }\end{array}$ \\
\hline $\begin{array}{l}\text { Moreira Júnior, } \\
\text { Zanella, Lopes \& } \\
\text { Seidel (2015) }\end{array}$ & $\begin{array}{l}\text { Avaliar a satisfação dos alunos das disciplinas de Estatística Básica e } \\
\text { Estatística Geral da Universidade Federal de Santa Maria, UFSM. }\end{array}$ \\
\hline $\begin{array}{l}\text { Nascimento, } \\
\text { Macedo, Siqueira \& } \\
\text { Bernardes (2016) }\end{array}$ & $\begin{array}{l}\text { Mensurar o traço latente do nível de alfabetização financeira dos discentes do } \\
\text { curso de Administração de Empresas de uma Instituição de Ensino Superior - } \\
\text { IES-Federal conduzida por uma survey com } 307 \text { alunos. }\end{array}$ \\
\hline $\begin{array}{l}\text { Nascimento, } \\
\text { Bernardes, Sousa e } \\
\text { Lourenço (2016) }\end{array}$ & $\begin{array}{l}\text { Mensurar o grau de satisfação de } 64 \text { alunos do curso de Ciências Contábeis } \\
\text { como ferramenta de avaliação de uma Instituição de Ensino Superior. }\end{array}$ \\
\hline Borges et al. (2017) & $\begin{array}{l}\text { Analisar o Miniquestionário de Qualidade de Vida em Hipertensão Arterial } \\
\text { realizado com } 712 \text { pessoas atendidas em } 13 \text { unidades de atenção primária em } \\
\text { saúde de Fortaleza, CE, Brasil. }\end{array}$ \\
\hline $\begin{array}{l}\text { Nascimento, } \\
\text { Barbosa \& Bizarria } \\
(2018)\end{array}$ & $\begin{array}{l}\text { Estimar os construtos latentes multidimensionais para mensurar o desempenho } \\
\text { de mercado das capacidades dinâmicas da orientação ambidestra, utilizando } \\
\text { uma survey com gestores de relações com investidores. }\end{array}$ \\
\hline
\end{tabular}

elaborado pelos autores

$\mathrm{Na}$ Tabela 4, destacam as aplicações da TRI no processo de avaliação do ensino-aprendizagem para os ingressantes nos cursos superiores (ENEM, FUVEST). Essas avaliações são realizadas com testes de múltipla escolha. Destacam também, as avaliações de mensuração de graus de satisfação e de traço latente do nível de alfabetização. Para Pasquali (1996), entre as inúmeras possíveis aplicações da TRI na teoria dos testes, algumas são especialmente relevantes, nas quais a TRI tem contribuições inovadoras e promissoras: banco de itens, testes a medida, equiparação de escores e identificação de itens enviesados.

\section{Software para aplicar a Teoria da Resposta ao Item (TRI)}

Considerado que a presente investigação objetiva discutir as contribuições da TRI para as avaliações de aprendizagem no ensino contábil e que a sua aplicação requer a utilização de softwares, a seguir são realizados alguns destaques. O Bilog- $M G^{\oplus}$, desenvolvido pela Scientific Software International (SSI, Inc.), para Andrade, Laros e Gouveia (2010), é um software que pode ser utilizado para a estimação dos modelos da TRI.

O software é uma extensão do Bilog 3 for Windows e é designado para análises de itens dicotômicos, incluindo itens de múltipla escolha ou itens de resposta curta pontuados como certo, errado, omisso ou não apresentado. Uma facilidade desse software é que todos os outputs (saídas com resultados) são apresentados em arquivos do tipo TXT, o que facilita a elaboração de relatórios, bem como a seleção de parâmetros de itens, no caso de fixação de parâmetros para equalização ou exportação para outros softwares como, por exemplo, o Testfact. 
De acordo com Luo e Jiao (2018), o Stan ${ }^{\circ}$ pode ser usado para três modelos representativos de TRI: o modelo logístico de três parâmetros, o modelo de resposta graduada e o modelo nominal de resposta. O Stan ${ }^{\oplus}$ é eficiente e requer tempo consideravelmente menor do que outros programas de software para estimar

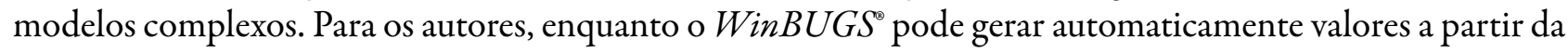
distribuição preditiva posterior para dados de resposta perdidos, o $\operatorname{Stan}^{\circ}$ trata todos os dados perdidos como parâmetros e consequentemente, um usuário $\operatorname{Stan}^{\oplus}$ deve defini-los no bloco de parâmetros ou no bloco de parâmetros transformados.

Para Yang e Zheng (2018), o desempenho do pacote da TRI disponível no Stata versão14 (2015) é conveniente para os pesquisadores aplicarem análises de dados rotineiramente conduzidas. Embora seja limitado a modelos TRI unidimensionais, o pacote funciona como uma boa plataforma onde os usuários podem calibrar e pontuar os dados de resposta do item. Além disso, os recursos gráficos podem ser bem apreciados pelos usuários.

Por fim, uma última alternativa (a presente lista não é exaustiva) ocorre com o Item Response Theory for Patient-Reported Outcomes - IRTPRO ${ }^{\oplus}$, também desenvolvido pela SSI, Inc. Além de possibilitar a estimação de modelos dicotômicos, politômicos (Resposta Gradual de Samejima), unidimensionais ou multidimensionais, o IRTPRO ${ }^{\circ}$ possibilita índices de qualidade de ajuste dos modelos (Goodness of Fit-GoF), a calibração dos testes, suportando, inclusive, a inserção de variáveis de controles (grupos de controle), bem como a condução de Análises Fatorial Exploratória, inclusive para itens dicotômicos. O IRTPRO ${ }^{\circ}$ utiliza os métodos Maximum Likelihood (ML) e Maximum a posteriori para estimação/calibração dos parâmetros dos itens.

Ademais, além de disponibilizar uma variedade de outputs em formatos de imagem (gráficos) e em arquivos do tipo TXT (a exemplo do Bilog- $M G^{\circ}$ ), o IRTPRO ${ }^{\circ}$ dispõe, também, de versões no formato .html. Como o IRTPRO ${ }^{\circ}$ apresenta versões acadêmicas que possibilitam a conduções de estudos, sem restrições, dentro do escopo de até 25 itens (o que, em tese, atende os requisitos avaliativos cotidianos da docência do ensino superior), bem como dispõe de manual bastante intuitivo. Nota-se que, na prática, se mostra como uma alternativa viável para a utilização cotidiana por parte dos docentes.

\section{Procedimentos metodológicos}

A metodologia utilizada foi de natureza analítico-descritiva. Foram analisados dados obtidos a partir do exame bibliográfico de forma qualitativa. Para a seleção da amostra foi utilizado o critério por acessibilidade de publicações que discutem questões relacionadas com o ensino superior e em especial com o ensino contábil e as aplicações diversas da TRI e como os docentes da área contábil poderá utilizá-la.

Foi utilizado os procedimentos da análise de conteúdo, que, segundo Bardin (2009), é um método que pode ser aplicado na investigação qualitativa. Para o autor a análise de conteúdo é realizada em três fases: 1) préanálise (fase de organização); 2) exploração do material (estudo do material); 3) tratamento dos resultados (a inferência e a interpretação).

$\mathrm{Na}$ fase da pré-análise, a coleta de dados foi realizada através de consultas em livros, artigos de periódicos, sítios eletrônicos e anais de congressos para selecionar o material mínimo necessário para compreender o fenômeno proposto na presente investigação. $\mathrm{Na}$ fase da exploração do material foi realizada um estudo aprofundado, buscando sínteses coincidentes e divergentes das ideias, às quais são relatadas no referencial teórico. A interpretação referencial (fase da reflexão - discussões) são apresentadas na discussão do resultado da pesquisa. 


\section{DISCUSSÃO DO RESULTADO DA PESQUISA}

Os objetivos desta investigação são analisados a seguir, a partir das discussões com a literatura relatada.

\section{Análises de questóes relacionadas com o ensino superior}

Os métodos de avaliação adotados pelos docentes e a coerência entre o que os docentes ensinam e a forma como avaliam a aprendizagem foram destaques nos estudos de Pereira e Flores (2012) e de Silva, Matos e Almeida (2014). Para estes últimos autores, buscar melhorias na avaliação em uma instituição escolar supõe pensar no objetivo de avaliar e nas funções da avaliação.

Ao trabalhar a questão prévia e fundamental com professores, nota-se que avaliar serve para medir o nível de aprendizagem obtido pelos alunos e para ajudar a melhorar o processo de ensino-aprendizagem dos mesmos. Os professores são os principais mediadores na elaboração do conceito de avaliação na mente dos alunos, incluindo também a sociedade como um todo. Porém, se não houver elaboração desse conceito, será formada uma ideia errônea do termo avaliação por parte desses alunos (Silva, Matos \& Almeida, 2014).

Os estudos de Batista e Ibiapina (2016), Picolli e Biavatti (2017), Leeuwenkamp, Brinke e Kester (2017), Keinänen, Ursin e Nissinen (2018) e Butler (2018) destacam preocupações com as práticas avaliativas, às quais devem ser realizadas com práticas dinâmicas. Os planos de ensino possuem deficiência sobre a definição de critérios de avaliação, sendo que as instituições de ensino superior têm a obrigação de garantir a qualidade da avaliação.

É necessário desenvolver ferramentas de avaliação para medir e desenvolver a capacidade de inovação de uma pessoa. Os testes de múltipla escolha ao serem utilizados deverão ser elaborados com o objetivo de fazer com que os alunos pensem de maneira produtiva para o seu aprendizado e que seja uma medida válida para determinar se a habilidade exigida foi adquirida.

A falta de conhecimento sobre as técnicas progressistas de ensino e o desconhecimento de métodos de ensino que mais eficazes para a aprendizagem dos alunos, foram tratadas nos textos de Almeida e Costa (2014), Brighenti, Biavatti e Souza (2015), Leal e Borges (2016), Gilioli et al. (2016) e Farias et al. (2018). Verifica-se assim, que é necessário conhecer e desenvolver novas técnicas.

\section{ANÁLISE DE QUESTÕES SOBRE O ENSINO CONTÁBIL}

A preocupação sobre questões relacionados com o ensino contábil foram abordadas por Slomkli (2007) e Andere e Araújo (2008). Contudo, observa-se nos estudos de Laffin e Gomes (2016) e Hillen, Laffin e Ensslin (2018) que a formação pedagógica dos docentes em Ciências Contábeis não melhorou.

Para esses últimos autores, a formação ainda não assume uma expressão de apropriação do trabalho para o ensinar. Deve haver um aprofundamento nos fundamentos epistemológicos para a formação desses professores com base em parcerias, buscando potencializar essa formação para além dos conteúdos da disciplina de Metodologia do Ensino e Estágios de Docência.

Os programas de pós-graduação em contabilidade no Brasil estão focados com a formação de pesquisadores e não com a docente e que a maioria dos docentes de Ciências Contábeis não aplicam ou não estão familiarizados com as técnicas progressista de ensino. Essas argumentações foram realizadas por Farias e Araújo (2016) e Almeida e Costa (2014). Entretanto, Farias et al. (2018) ainda ratifica a necessidade do aperfeiçoamento da prática docente. Desse modo, observa-se a necessidade de encontrar métodos para melhorar a relação entre ensino-aprendizagem para os futuros contadores e contadoras no Brasil. 


\section{Análise sobre aplicações diversas da Teoria da Resposta ao Item}

Os estudos de Andriola (2011), Bortolotti et al. (2012), Nascimento, Nossa e Balassiano (2013), Barbetta, Trevisan, Tavares e Azevedo (2014), Nascimento, Macedo, Siqueira e Bernardes (2016), Rusch, Lowry, Mair e Treiblmaier (2017), Huang et al. (2017), Vincenzi et al. (2018), Muñoz-Merino, Novillo e Kloos (2018) e Uto e Ueno (2018) relatam casos de aplicação da Teoria da Resposta ao Item --TRI-.

Segundo esses autores, a TRI pode ser usada para medir habilidades e competências do ENEM; como escala de medida de satisfação de alunos e percepção de indicadores de sustentabilidade. É usada também para investigar o analfabetismo funcional e alfabetização financeira; para selecionar traços latentes predominantes, variáveis latentes contínuas e itens mais informativos; para contribuir na avaliação de habilidades e de desempenho, dentre outras aplicações.

Segundo Andriola (2011), do ponto de vista estritamente técnico, os parâmetros métricos dos itens da prova do ENEM são determinados a partir de modelos matemáticos subjacentes à TRI. O ENEM é um modelo de seleção de estudantes concebido para avaliar habilidades e competências humanas. As habilidades se referem às aptidões intrínsecas aos humanos.

O ENEM busca avaliar competências mais complexas também, tais como: domínio de linguagens; compreensão de fenômenos; enfrentamento de situações-problema; construção de argumentações e elaboração de propostas. Estas competências devem ser desenvolvidas através da mediação da escola para serem empregadas pelos futuros universitários, sobretudo com vistas à geração de novos conhecimentos científicos, proposição de ações factíveis para resolver problemas sociais, promoção da inovação tecnológica, dentre outras.

\section{Análises sobre aplicações da TRI no ensino contábil brasileiro}

Pode-se verificar, após os relatos dos textos analisados nos Tabelas 3 e 4 e nos livros de Pasquali (1996) e de Andrade, Tavares e Valle (2000) que a TRI têm aplicações práticas para os docentes dos cursos de graduação em Ciências Contábeis nas avaliações das diversas disciplinas que compõem a grade curricular do curso, como em: Teoria da Contabilidade, Contabilidade Intermediária, Contabilidade Avançada, Contabilidade Governamental, Análise de Custos, Controladoria, Mercado Financeiro, Finanças Corporativas, dentre outras. As disciplinas possuem uma carga teórica e prática que permitem que sejam elaboradas questões de respostas binárias; escalas de resposta Likert etc. para aplicar a TRI.

Instrumentalizados pela técnica TRI, os docentes poderão desenvolver avaliações coerentes com as competências e habilidades inerentes à formação profissional em contabilidade, por meio de testes que capturam os parâmetros de dificuldade, discriminação e, sobretudo, de acerto casual dos itens, inclusive com maior "justiça”, uma vez que a TRI reduz a subjetividade inerente a determinadas questóes (sobretudo subjetivas/"abertas", e, sobretudo, e que, por meio da criação do banco de itens, possibilita a aplicação de provas equivalentes (em termos de parâmetros $a_{i}, b_{i}$ e $c_{i}$ ) em datas distintas (especialmente útil para provas alternativas/substitutas). Ademais, torna-se possível o acompanhamento longitudinal do nível em função de múltiplos fatores, como, por exemplo, as metodologias de ensino adotadas, práticas de ensino/aprendizagem e da utilização de recursos diversos (computacionais, educacionais, entre outros). Logo, a TRI possibilita, inclusive, a captura da contribuição do professor na evolução do nível .

A técnica TRI pode, também, ser aplicada como um pré-exame (preparatório) para o Exame Nacional de Desempenho dos Estudantes -ENADE-. O ENADE tem como objetivo o acompanhamento do processo de aprendizagem e do desempenho acadêmico dos estudantes em relação aos conteúdos programáticos previstos nas diretrizes curriculares do respectivo curso de graduação. É aplicado periodicamente aos estudantes de todos os cursos de graduação, durante o primeiro (ingressantes) e último (concluintes) ano do curso. 
Outra aplicação se refere ao preparatório dos alunos do último ano do curso de graduação para fazerem o Exame de Suficiência Contábil. Este exame é realizado pelo Conselho Federal de Contabilidade como requisito necessário para os futuros contadores exercerem suas atividades. $\mathrm{O}$ exame é composto de 50 questões com quatro alternativas de respostas.

\section{CONSIDERAÇÕES FINAIS}

As instituições de ensino superior têm a obrigação de garantir a qualidade da avaliação. No entanto, esta é uma tarefa difícil porque não existe uma conceituação clara e abrangente da qualidade da avaliação. As ferramentas de avaliação devem medir e desenvolver a capacidade de inovação de uma pessoa. $O$ processo de aprendizagem e as avaliações devem levar o aluno a pensar e a buscar o conhecimento necessário para que tenha as habilidades e competências para o exercício da profissão escolhida.

Os objetivos desta investigação foram analisar as contribuições de publicações que discutem questões relacionadas com o ensino superior e de modo especial o ensino contábil e as aplicações diversas da Teoria da Resposta ao Item -TRI-. O objetivo principal foi discutir as contribuições da aplicação da TRI nas avaliações de aprendizagem do ensino contábil brasileiro e como os docentes poderá utilizá-la.

Pode-se afirmar que os objetivos foram alcançados. Neste sentido, os principais achados foram:

- As práticas de avaliação precisam ser elevadas à condição estratégica nos processos de formação docente;

- A titulação de mestre e/ou doutor nos programas Strito Sensu de contabilidade não oferece a capacitação necessária para o exercício da docência;

- É necessário desenvolver práticas pedagógicas e ferramentas de avaliação;

- A TRI ao ser aplicada nos testes de múltipla escolha das diversas disciplinas do curso de graduação em Ciências Contábeis (Teoria da Contabilidade; Contabilidade Intermediária; Contabilidade Avançada; Contabilidade Governamental etc.) e em testes dissertativos serve para avaliar as competências e habilidades exigidas para a formação profissional do contador.

Finalizando, observa-se que este estudo contribui com a literatura que trata da formação dos docentes do Curso de Graduação em Ciências Contábeis. Recomenda-se a realização de mais estudos sobre os processos de avaliação no ensino superior, além de estudos que divulguem casos práticos da aplicação da TRI no processo das avaliações de aprendizagem do ensino contábil brasileiro.

\section{Referências}

Allega, O., Leng, X., Vaccarino, A., Skelly, M., Lanzini, M., Hidalgo, M., Soares, C., Kennedy, S., \& Frey, B. (2018). Performance of the biological rhythms interview for assessment in neuropsychiatry: An item response theory and actigraphy analysis. Journal of Affective Disorders, 225, 54-63. DOI: http://dx.doi.org/10.1016/ j.jad.2017.07.047

Almeida, S. R., \& Costa, T. A. (2014). A familiaridade dos professores de Ciências Contábeis com diferentes técnicas de ensino: uma análise nas Universidades Públicas do Rio de Janeiro. Revista de Educação, Gestão e Sociedade, 15, 1-19.

Andere, M. A., \& Araújo, A. M. (2008). Aspectos da formação do professor de ensino superior de ciências contábeis: uma análise dos programas de pós-graduação. Revista Contabilidade \& Finanças, 19(48), 91-102.

Andrade, D. F., Tavares, H. R., \& Valle, R. C. (2000). Teoria da Resposta ao Item: Conceitos e Aplicações. São Paulo: Associação Brasileira de estatística, SINAPE.

Andrade, J. M., Laros, J. A., \& Gouveia, V. V. (2010). O uso da teoria de resposta ao item em avaliações educacionais: diretrizes para pesquisadores. Avaliação Psicológica, 9(3), 421-435.

Andriola, W. B. (2011). Doze motivos favoráveis à adoção do Exame Nacional do Ensino Médio (ENEM) pelas Instituições Federais de Ensino Superior (IFES). Ensaio: aval. pol.públ. Educ., 19(70), 107-126. 
Anthony, C. J., DiPerna, J. C., \& Lei, P. W. (2016). Maximizing measurement efficiency of behavior rating scales using Item Response Theory: An example with the social skills improvement system - Teacher rating scale. Journal of School Psychology, 55, 57-69. DOI: http://dx.doi.org/10.1016/j.jsp.2015.12.005

Araújo, A. O., \& Moraes Júnior, V. F. (2012). Avaliação da aprendizagem: uma experiência do uso do portfólio em uma disciplina do curso de ciências contábeis. Revista Ambiente Contábil, 4(1), 36-50.

Araújo, E. A., Andrade, D. F., \& Bortolotti, S. L. (2009). Teoria da Resposta ao Item. Rev Esc Enferm USP, 43(spe), 1000-1008.

Ayala, R. J., \& Santiago, S. Y. (2017). An introduction to mixture item response theory models. Journal of School Psychology, 60, 25-40. DOI: http://dx.doi.org/10.1016/j.jsp.2016.01.002

Ayis, S. A., Ayerb, L., Ashworth, M., \& Wolfe, C. D. (2018). Evaluation of the Hospital Anxiety and Depression Scale (HADS) in screening stroke patients for symptoms: Item Response Theory (IRT) analysis. Journal of Affective Disorders, 228, 33-40. DOI: https://doi.org/10.1016/j.jad.2017.11.037

Baker, F. B. (2001). The basics of item response theory. New York: ERIC Clearinghouse on Assessment and Evaluation.

Barbetta, P. A., Trevisan, L. M., Tavares, H., \& Azevedo, T. C. (2014). Aplicação da teoria da resposta ao item uni e multidimensional. Est. Aval. Educ., 25(57), 280-302.

Bardin, L. (2009). Análise de Conteúdo. Lisboa: Edições 70, LDA.

Batista, S. M., \& Ibiapina, I. M. (2016). Possibilidades da prática avaliativa no ensino superior: uma experiência colaborativa. Revista Ibero-Americana de Estudos em Educação, 11(4), 1994-2011. DOI: http:// dx.doi.org/10.21723/riaee.v11.n4.7392

Borba, A. M., Ferri, C., \& Hostins, R. C. (2007). Avaliação da aprendizagem no ensino superior: questões que emergem da prática docente. Contrapontos, 7(1), 43-54.

Borges, J., Moreira, T., Schmitt, J., Andrade, D., Barbetta, P., Souza, A., Lima, D., \& Carvalho, I. (2017). Medição da qualidade de vida em hipertensão arterial segundo a Teoria da Resposta ao Item. Rev Saúde Pública, 51, maio 04. DOI: https://doi.org/10.1590/S1518-8787.2017051006845

Bortolotti, S., Moreira Júnior, F., Bornia, A., Sousa Júnior, A., \& Andrade, D. (2012). Avaliação do nível de satisfação de alunos de uma instituição de ensino superior: uma aplicação da Teoria da Resposta ao Item. Gestão e Produção, 19(2), 287-302.

Brighenti, J., Biavatti, V. T., \& Souza, T. R. (2015). Metodologias de ensino aprendizagem: uma abordagem sob a percepção dos alunos. Revista GUAL, 8(3), 281-304. DOI: http:// dx.doi.org/10.5007/1983-4535.2015v8n3p281

Butler, A. C. (2018). Multiple-choice testing in education: Are the best practices for assessment also good for learning? Journal of Applied Research in Memory and Cognition, 7(3), 323-331. DOI: https://doi.org/10.1016/ j.jarmac.2018.07.002

Crowe, M., Sleep, C., Carter, N., Campbell, W., \& Miller, J. (2018). Self-esteem and narcissism: An item response theory analysis of curvilinearity. Personality and Individual Differences, 128, 16-20. DOI: https:// doi.org/10.1016/j.paid.2018.02.016

Farias, R., \& Araújo, A. (2016). Percepção dos professores de contabilidade quanto aos espaços formativos para o ofício da docência no Brasil. Revista de Contabilidade e Organizaçôes, 28, 59-70. DOI: http://dx.doi.org/10.11606/ rco.v10i28.124789

Farias, R., Lima, J., Vendramin, E., Aráujo, A., \& Zanini, R. (2018). O que é ser um bom professor? Análise das competências docentes pela ótica discente. Revista Mineira de Contabilidade, 19(3), 15-27. DOI: https:// doi.org/10.21714/2446-9114RMC2018v19n3t02

Garcia, J. (2009). Avaliação e aprendizagem na educação superior. Estudos em Avaliação Educacional, 20(43), 201-213.

Gifford, K., Liu, D., Romano, R., Jones, R., \& Jefferson, A. (2015). Development of a subjective cognitive decline questionnaire using item response theory: A pilot study. Alzheimer's \& Dementia: Diagnosis, Assessment \& Disease Monitoring, 1, 429-439. DOI: http://dx.doi.org/10.1016/j.dadm.2015.09.004 
Gilioli, A., Cassaro, M., Santos, F., Amaral, P., Cardoso, R., \& Benedicto, G. (2016). Ensino-aprendizagem na área da educação contábil: uma investigação teórico-empírica. RISUS - Journal on Innovation and Sustainability, 7(3), 3-28.

Hambleton, R. K., Swaminathan, H., \& Rogers, H. J. (1991). Fundamentals of item response theory. Newbury Park: Sage Publications.

Harvey, R. J. (2016). Improving Measurement via Item Response Theory: Great Idea, But Hold the Rasch. The Counseling Psychologist, 44(2), 195-204. DOI: http://dx.doi.org/10.1177/0011000015615427

Heafner, T. L., \& Fitchett, P. G. (2018). US history content knowledge and associated effects of race, gender, wealth, and urbanity: Item Response Theory (IRT) modeling of NAEP-USH achievement. Journal of Social Studies Research, 42, 11-25. DOI: https://doi.org/10.1016/j.jssr.2017.01.001

Hillen, C., Laffin, M., \& Ensslin, S. R. (2018). Proposições sobre formação de professores na área contábil. Arquivos Analiticos de Politicas Educativas, 26(106), 81-98. DOI: http://dx.doi.org/10.14507/epaa.26.3060

Hoertel, N., Peyre, H., Lavaud, P., Blanco, C., Guerin-Langlois, C., René, M., Schuster, J. P., Lemogne, C., Delorme, R., \& Limosin, F. (2018). Examining sex differences in DSM-IV-TR narcissistic personality disordersymptom expression using Item Response Theory (IRT). Psychiatry Research, 260, 500-507. DOI: https://doi.org/10.1016/j.psychres.2017.12.031

Huang, Y., Lee, J., Chen, Z., Perry, M., Cheung, J., \& Wang, M. (2017). An item-response theory approach to safety climate measurement: The liberty mutual safety climate short scales. Accident Analysis and Prevention, 103, 96-104. DOI: https://doi.org/10.1016/j.aap.2017.03.015

Hung, S. P. (2018). Validating the creative self-efficacy student scale with a Taiwanese sample: An item response theory-based investigation. Thinking Skills and Creativity, 27, 190-203. DOI: https://doi.org/10.1016/ j.tsc.2018.02.006

INEP, Instituto Nacional de Estudos e Pesquisas Educacionais Anísio Teixeira (2011). Procedimento de cálculo das notas do Enem. Disponível em: < http://download.inep.gov.br/educacao_basica/enem/nota_tecnica/2011/ nota_tecnica_procedimento_de_calculo_das_notas_enem_2.pdf $>$. Acesso em 13 Jan. 2019.

Keinänen, M., Ursin, J., \& Nissinen, K. (2018). How to measure students' innovation competences in higher education: Evaluation of an assessment tool in authentic learning environments. Studies in Educational Evaluation, 58, 30-36. DOI: https://doi.org/10.1016/j.stueduc.2018.05.007

Laffin, M., \& Gomes, S. M. (2016). Formação do professor de contabilidade: O tema em debate. Arquivos Analíticos de Politicas Educativas, 24(77). DOI: http://dx.doi.org/10.14507/epaa.24.2372

Leal, E., \& Borges, M. (2016). Estratégias de ensino aplicadas na área da contabilidade gerencial: um estudo com discentes do curso de ciências contábeis. Revista Ambiente Contábil, 8(2), 1-18.

Leeuwenkamp, K. J., Brinke, D. J., \& Kester, L. (2017). Assessment quality in tertiary education: An integrative literature review. Studies in Educational Evaluation, 55, 94-116. DOI: http://dx.doi.org/10.1016/ j.stueduc.2017.08.001

Lord, F. M., \& Novick, M. R. (1968). Statistical theories of mental test scores. Reading, MA: Addison Wesley.

Luo, Y., \& Jiao, H. (2018). Using the Stan program for Bayesian item response Theory. Educational and Psychological Measurement, 78(3), 384-408. DOI: http://dx.doi.org/10.1177/0013164417693666

Machado, D. C., \& Barbetta, P. A. (2015). Aplicação da Teoria de Resposta ao Item nos questionários de contextualização do Saeb 2011. Anais ... IV Conbratri - Congresso Brasileiro de Teoria da Resposta ao Item No 2, 49-72.

Marino, M., Dore, E., Ni, P., Ryan, C., Schneider, J., Acton, A., Jette, A., \& Kazis, L. (2018). Developing Item Response Theory - Based short forms to measure the social impact of burn injuries. Archives of Physical Medicine and Rehabilitation, 99, 521-528. DOI: https://doi.org/10.1016/j.apmr.2017.06.037

Matos, D. A., Cirino, S. D., Brown, G. T. L., \& Leite, W. L. (2013). Avaliação no ensino superior: concepções múltiplas de estudantes brasileiros. Estudos em Avaliação Educacional, 24(54), 172-193. 
Matzembacher, D. E., Stangherlin, I. C., Slongo, L. A., \& Cataldi, R. (2018). An integration of traceability elements and their impact in consumer's trust. Food Control, 92, 420-429. DOI: https://doi.org/10.1016/ j.foodcont.2018.05.014

Moreira Júnior, F. J. (2010). Aplicações da teoria da resposta ao item (TRI) no Brasil. Revista Brasileira de Biometria, 28(4), 137-170.

Moreira Júnior, F. J., Zanella, A., Lopes, L. F. D., \& Seidel, E. J. (2015). Avaliação da satisfação de alunos por meio do Modelo de Resposta Gradual da Teoria da Resposta ao Item. Ensaio: aval. pol. públ. Educ., 23(86), 129-158.

Muñoz-Merino, P. J., Novillo, R. G., \& Kloos, C. D. (2018). Assessment of skills and adaptive learning for parametric exercises combining knowledge spaces and item response theory. Applied Soft Computing, 68, 110-124. DOI: https://doi.org/10.1016/j.asoc.2018.03.045

Nascimento, J. C. H. B., Barbosa, F. L. S., \& Bizarria, F. P. A. (2018). Orientação Ambidestra: Uma Proposição de Operacionalização por Meio da Teoria de Resposta ao Item. In: XLII Encontro da ANPAD, Anais... Curitiba-PR.

Nascimento, J. C., Bernardes, J. R., Sousa, W. D., \& Lourenço, R. L. (2016). Avaliação Institucional: Aplicação da Teoria da Resposta ao Item para avaliação discente em Ciências Contábeis. Future Studies Research Journal, 8(2), 117-143.

Nascimento, J. C., Macedo, M. A., Siqueira, J. R., \& Bernardes, J. R. (2016). Alfabetização financeira: um estudo por meio da aplicação da teoria de resposta ao item. Administração: Ensino e Pesquisa, 17(1), 147-175. DOI: http:// dx.doi.org/10.13058/raep.2016.v17n1.341

Nascimento, J. C., Nossa, V., \& Balassiano, M. (2013), O Analfabetismo Funcional e a Contabilidade: Um Estudo Exploratório com Alunos Concluintes da Graduação das Instituições de Ensino Superior do Estado do Espírito Santo. Sociedade, Contabilidade e Gestão, 8(3), 37-54.

Obbarius, N., Fischer, F., Obbarius, A., Nolte, S., Liegl, G., \& Rose, M. (2018). A 67-item stress resilience item bank showing high content validity was developed in a psychosomatic sample. Journal of Clinical Epidemiology, 100, 1-12. DOI: https://doi.org/10.1016/j.jclinepi.2018.04.004

Ott, E., Cunha, J. V., Cornacchione Júnior, E. B., \& De Luca, M. M. (2011). Relevância dos conhecimentos, habilidades e métodos instrucionais na perspectiva de estudantes e profissionais da área contábil: estudo comparativo internacional. Revista Contabilidade \& Finanças - USP, 22(57), 338-356.

Pasquali, L. (1996). Teoria da resposta ao item - IRT: uma Introdução. In: Pasquali, L. (Org). Teoria e métodos de medida em ciências do comportamento. Brasília: Laboratório de Pesquisa em Avaliação e Medida, Instituto de Psicologia - UnB: INEP.

Peleias, I. R., Mendonça, J. F., Slomski, V. G., \& Fazenda, I. C. (2011). Interdisciplinaridade no ensino superior: análise da percepção de professores de controladoria em cursos de ciências contábeis na cidade de São Paulo. Avaliação, 16(3), 499-532.

Pereira, D. R., \& Flores, M. A. (2012). Percepções dos estudantes universitários sobre a avaliação das aprendizagens: um estudo exploratório. Avaliação, 17(2), 529-556.

Picolli, M. R., \& Biavatti, V. T. (2017). Avaliação da aprendizagem no curso de ciências contábeis: uma abordagem a partir dos instrumentos avaliativos dos planos de ensino das disciplinas do eixo profissional. Revista Brasileira de Contabilidade, 225, 52-65.

Pinheiro, P. M., \& Santos, R. R. (2012). Avaliação da aprendizagem no Ensino Superior: perspectivas críticas ou técnicas? Polyphonía, 23/1.

Popescu-Mitroia, M. M., Todorescu, L. L., \& Greculescu, A. (2015). The usefulness of portfolios as assessment tools in higher education. Procedia - Social and Behavioral Sciences, 191, 2645-2649. DOI: https://doi.org/10.1016/ j.sbspro.2015.04.722

Pryjma, M. F., \& Oliveira, O. S. (2016). O desenvolvimento profissional dos professores da educação superior: reflexões sobre a aprendizagem para a docência. Educ. Soc., Campinas, 37(136), 841-857. DOI: http:// dx.doi.org/10.1590/ES0101-73302016151055 
Quaresma, E. S., Barbetta, P. A., Borgatto, A. F., Bautista, E. A. L., \& Dias, C. T. S. (2014). Construção de escalas de proficiência para exames seletivos, por meio da Teoria da Resposta ao Item. Revista da Estatística da Universidade Federal de Ouro Preto, 3, 328-332.

Reckase, M. D. (2009). Statistics for Social and Behavioral Sciences: Multidimensional Item Response Theory. Springer: New York.

Rodrigues, M. T., Moreira, T. M., Vasconcelos, A. M., Andrade, D. F., Silva, D. B., \& Barbetta, P. A. (2013). Instrumento mensurador de adesão para hipertensos: contribuição da Teoria da Resposta ao Item. Revista de Saúde Pública, 47, 523-530. DOI: https://doi.org/10.1590/S0034-8910.2013047004439

Rusch, T., Lowry, P. B., Mair, P., \& Treiblmaier, H. (2017). Breaking free from the limitations of classical test theory: Developing and measuring information systems scales using item response theory. Information \& Management, 54, 189-203. DOI : http://dx.doi.org/10.1016/j.im.2016.06.005

Sabbag, P. Y., Bernardi JR, P., Goldszmidt, R., \& Zambaldi, F. (2010). Validação de Escala para Mensurar Resiliência por Meio da Teoria de Resposta ao Item (TRI). In XXXIV EnANPAD, Rio de Janeiro. Anais ... EnANPAD.

Schivinski, B., Brzozowska-Wos, M., Buchanan, E. M., Griffiths, M. D., \& Pontes, H. M. (2018). Psychometric assessment of the Internet Gaming Disorder diagnostic criteria: An Item Response Theory study. Addictive Behaviors Reports, 8, 176-184. DOI: https://doi.org/10.1016/j.abrep.2018.06.004

Sekely, A., Taylor, G. J., \& Bagby, R. M. (2018). Developing a short version of the Toronto Structured Interview for Alexithymia using item response theory. Psychiatry Research, 266, 218-227. DOI: https://doi.org/10.1016/ j.psychres.2018.03.002

Silva, D. S., Matos, P. M., \& Almeida, D. M. (2014). Métodos avaliativos no processo de ensino e aprendizagem: uma revisão. Cadernos de Educação, 47, 73-84.

Slomski, V. G. (2007). Saberes e competências do professor universitário: contribuições para o estudo da prática pedagógica do professor de ciências contábeis do brasil. RCO - Revista de Contabilidade e Organizaçôes, 1(1), 87-103.

Sordi, M. R., \& Ludke, M. (2009). Da avaliação da aprendizagem à avaliação institucional: aprendizagens necessárias. Avaliação, 14(2), 313-336.

Souza, A. M. (2012). Avaliação da aprendizagem no ensino superior: aspectos históricos. Revista Exitus, 2(1), 231-254.

Toland, M. D. (2014). Practical guide to conducting an item response theory analysis. Journal of Early Adolescence, 34(1), 120-151. DOI: http://dx.doi.org/10.1177/0272431613511332

Tracey, T. J., \& Tao, C. (2018). Response latency in interest assessment: An added tool? Journal of Vocational Behavior, 108, 121-131. DOI: https://doi.org/10.1016/j.jvb.2018.07.001

Turra, C. M., Enricone, D., Sant'Anna, F. M., \& André, L. C. (1989). Planejamento de ensino e avaliação. 11. ed., Porto Alegre: Editora Sagra Luzzatto.

Uto, M., \& Ueno, M. (2018). Empirical comparison of item response theory models with rater's parameters. Psychology, Information Science, 4(5), DOI : https://doi.org/10.1016/j.heliyon.2018.e00622

Vendramini, C. M. M., \& Dias, A. S. (2005). Teoria de Resposta ao Item na análise de uma prova de estatística em universitários. Psico-USF, 10(2), 201-210.

Vincenzi, S. L., Possan, E., Andrade, D. F., Pituco, M. M.,Santos, T. O., \& Jasse, E. P. (2018). Assessment of environmental sustainability perception through item response theory: A case study in Brazil. Journal of Cleaner Production, 170, 1369-1386. DOI: https://doi.org/10.1016/j.jclepro.2017.09.217

Yang, J. S., \& Zheng, X. (2018). Item Response Data Analysis Using Stata Item Response Theory Package. Journal of Educational and Behavioral Statistics, 43(1), 116-129. DOI: http://dx.doi.org/10.3102/1076998617749186

\section{Notas}

* $\quad$ Artigo de pesquisa científica.

Licencia Creative Commons CC BY 4.0 